\title{
Influência da taxa de congelamento no comportamento físico-químico e estrutural durante a liofilização da albumina bovina
}

\author{
Virgilio Tattini Jr. ${ }^{1}$, Duclerc Fernandes Parra², Ronaldo Nogueira de Moraes Pitombo ${ }^{1, *}$ \\ ${ }^{1}$ Departamento de Tecnologia Bioquímico-Farmacêutica, Faculdade de Ciências Farmacêuticas, Universidade de São \\ Paulo, 2 Instituto de Pesquisas Energéticas e Nucleares, IPEN
}

*Correspondência:

R. N. de M. Pitombo

Departamento de Tecnologia

Bioquímico-Farmacêutica

Faculdade de Ciências Farmacêuticas Av. Prof. Lineu Prestes, 580, Bloco 16, 05508-900 - São Paulo, SP - Brasil E-mail pitombo@usp.br
A liofilização é o método mais comumente utilizado para a preparação de proteinas desidratadas, as quais devem apresentar estabilidade adequada por longo período de armazenagem em temperaturas ambientes. Entretanto, estudos recentes com espectroscopia no infravermelho têm documentado que os problemas relacionados com o congelamento e a desidratação induzidos pela liofilização podem levar ao desdobramento molecular da proteína. Através de análises por espectroscopia Raman, associadas com análise térmica por calorimetria exploratória diferencial (DSC), estudou-se a influência da taxa de congelamento no comportamento físico-químico e estrutural da albumina sérica bovina submetida ao processo de liofilização. Observou-se que a albumina liofilizada com taxa de congelamento de $2,5^{\circ} \mathrm{C} / \mathrm{min}$ apresentou maior alteração estrutural quando comparada à albumina liofilizada com taxa de congelamento de $30{ }^{\circ} \mathrm{C} / \mathrm{min}$, a qual apresentou menores oscilações espectrais nas regiões da amida I, III e pontes de dissulfeto, favorecendo a manutenção da conformação estrutural da proteína.
Unitermos

- Liofilização

- Espectroscopia

- Raman

- Calorimetria exploratória diferencial

\section{INTRODUÇÃO}

As soluções protéicas são facilmente desnaturadas (muitas vezes irreversivelmente) pelo aparecimento de numerosos eventos que podem afetar a estabilidade das soluções, tais como: aquecimento, agitação, congelamento, mudanças no $\mathrm{pH}$ e exposição a interfaces ou agentes desnaturantes, resultando geralmente na perda da eficácia clínica e no aumento do risco de efeitos colaterais adversos. Mesmo se a estabilidade física for mantida, as proteínas podem ser degradadas por reações químicas, como, por exemplo, hidrólise e desamidação, muitas das quais são mediadas pela água (Carpenter et al., 1999). O aumen- to da estabilidade de proteínas pode ser obtido através da remoção da água (desidratação).

A liofilização é o método mais comumente utilizado para a preparação de proteínas desidratadas, as quais devem apresentar estabilidade adequada por longo período de armazenagem em temperaturas ambientes. A liofilização é um processo de secagem constituído de três etapas: congelamento, secagem primária e secagem secundária. A finalidade do congelamento dentro do processo de liofilização consiste na imobilização do produto a ser liofilizado, interrompendo reações químicas e atividades biológicas. O material, previamente congelado, é desidratado por sublimação seguida pela dessorção, utilizando-se baixas temperaturas de secagem a 
pressões reduzidas. A estrutura e forma do produto, assim como a taxa de sublimação, são determinadas pelo processo de congelamento. A estrutura não deve ser alterada durante o processo de liofilização para se evitar a ocorrência de danos irreversíveis ou a perda do produto. O congelamento é uma das etapas mais críticas do processo de liofilização (Murgatroyd et. al., 1997).

Um parâmetro importante que precisa ser definido durante o congelamento é a taxa de congelamento. O grau de desnaturação protéica induzida pelo congelamento é uma função complexa, tanto da taxa de congelamento como da temperatura final obtida. Os efeitos relacionados com as taxas de congelamento na estabilidade das proteínas variam de forma significativa. Eckhardt et al. (1991), estudaram o comportamento estrutural do hormônio do crescimento recombinante $(\mathrm{rGH})$ em $2 \mathrm{mg} / \mathrm{ml}$ e em $5 \mathrm{mM}$ de tampão fosfato ( $\mathrm{pH} \mathrm{7,4} \mathrm{ou} \mathrm{7,8)}$ em relação ao aumento da taxa de congelamento de 0,5 para $50{ }^{\circ} \mathrm{C} / \mathrm{min}$. Esta variação na taxa de congelamento não induziu à agregação protéica, entretanto verificou-se a formação de desdobramento protéico mesmo na presença de mais de $250 \mathrm{mM}$ de manitol. O congelamento rápido foi responsável pela formação em maior quantidade de agregados insolúveis para a imunoglobulina bovina ( $\operatorname{IgG}$ bovino) e humana ( $\operatorname{IgH})$, quando comparado ao congelamento lento. Esta característica deve-se à formação de pequenos cristais de gelo, conseqüentemente, maiores interfaces de gelo/água em taxas de congelamento mais altas, levando a maior extensão de desnaturação protéica. Por outro lado, o congelamento rápido causou menor perda da atividade da enzima Lactato Desidrogenase (LDH) e menores mudanças na estrutura secundária da hemoglobina em solução de PEG/dextran. A reduzida diminuição da atividade protéica deve-se a maior taxa de congelamento, capaz de impedir o crescimento abrangente dos cristais, retardando substancialmente a desnaturação protéica frente a crioconcentração induzida na solução. Além disso, a influência das taxas de congelamento sobre a estabilidade das proteínas é dependente dos mecanismos de desnaturação predominantes (Wang, 2000).

A liofilização pode causar diversas mudanças estruturais no espectro das proteínas. Estudos recentes com espectroscopia no infravermelho têm documentado que os problemas relacionados com o congelamento e a desidratação induzidos pela liofilização podem levar ao desdobramento molecular da proteína. Roy e Gupta (2004), através de análises por espectroscopia infravermelho, principalmente por transformada de Fourier, estudaram as alterações estruturais nas proteínas após a liofilização. Geralmente, a secagem de uma proteína induz à diminuição das estruturas de $\alpha$-hélice e desordenadas e ao aumento nas estruturas folhas- $\beta$. Os pesquisadores notaram que no caso das proteínas dos fatores estimulantes dos fibroblastos e do $\gamma$-interferona, a espectroscopia no infravermelho acusou mudanças conformacionais notáveis e sinais de agregação durante a liofilização, problema este que poderia ser reduzido através da utilização de lioprotetores. Deve-se enfatizar que a liofilização não pode ser considerada como processo inofensivo, necessitando de total controle e conhecimento de todas as etapas envolvidas. Durante a análise espectroscópica, a informação estrutural pode ser obtida pelo estudo da faixa na região da amida I conformacionalmente sensível, que se situa entre 1.600 e $1.700 \mathrm{~cm}^{-1}$. Esta banda é sensível ao estiramento vibracional das ligações $\mathrm{C}=\mathrm{O}$, fracamente ligadas ao estiramento $\mathrm{C}-\mathrm{N}$ e N-H. Cada tipo de estrutura secundária ( $\alpha$-hélice, folhas- $\beta$ e estruturas desordenadas) causam o aumento de uma freqüência de estiramento de $\mathrm{C}=\mathrm{O}$ diferente e, portanto, apresentam uma posição de faixa característica, a qual é designada pelo número da onda $\mathrm{em}^{\mathrm{cm}^{-1}}$. As posições das faixas são usadas para determinar os tipos estruturais secundários presentes em uma proteína. As áreas de faixa relativa podem, então, ser utilizadas para quantificar cada componente estrutural. Conseqüentemente, a análise das faixas por espectroscopia no infravermelho na região da amida I pode fornecer informação tanto quantitativa como qualitativa sobre a estrutura secundária da proteína. O desdobramento protéico causado pelo processo de liofilização não somente pode levar à redução da estabilidade durante o armazenamento da proteína liofilizada, mas também pode levar à desnaturação irreversível da proteína (Carpenter et al., 1999). A perda das ligações de hidrogênio nas proteínas durante a liofilização geralmente leva ao aumento na freqüência e à diminuição na intensidade das faixas de expansão da hidroxila. O desdobramento das proteínas durante a liofilização amplia e modifica (para números de ondas maiores) as bandas dos componentes da amida I. A liofilização freqüentemente conduz ao aumento no conteúdo de folhas- $\beta$ com uma redução concomitante no conteúdo de $\alpha$-hélice. A conversão da $\alpha$-hélice para folhas- $\beta$ durante a liofilização tem sido observada em muitas proteínas, tais como o toxóide tetânico (TT) em $10 \mathrm{mM}$ de tampão de fosfato de sódio ( $\mathrm{pH} 7,3$ ), albumina humana recombinante (AHr) em soluções com diferentes tampões e em diferentes $\mathrm{pH}$, hormônio do crescimento humano $(\mathrm{GHh}) \mathrm{em}$ pH 7,8 e sete proteínas modelo em solução, incluindo o inibidor tripsina pancreática bovina (ITPB), o 
quimiotripsinogênio, a mioglobina de cavalo (Mb), o citocromo $\mathrm{C}$ cardíaco eqüino ( $\mathrm{CytC})$, a $\mathrm{AHr}$, a insulina suína e a ribonuclease A (RNase A) (Griebenow, Klibanov, 1995).

Utilizando-se espectroscopia Raman para a determinação da estrutura secundária do anticorpo recombinante monoclonal humano, Sane et al. (2004) observaram significativas perturbações estruturais após a liofilização da proteína sem a presença de aditivos lioprotetores. O conteúdo das estruturas de folhas- $\beta$ diminuiu proporcionalmente em relação ao aumento das estruturas desordenadas. Os resultados demonstraram que a região da amida I na espectroscopia Raman pode ser considerada como ferramenta confiável e rápida nos estudos da conformação estrutural protéica.

O mecanismo da liofilização, congelamento seguido de secagem por sublimação, induz à obtenção de produtos que em sua maioria estão no estado amorfo. Devido à natureza amorfa da proteína e dos agentes estabilizantes geralmente usados (açúcares ou polióis), as formulações liofilizadas exibem freqüentemente o fenômeno da transição vítrea, um importante parâmetro para o desenvolvimento do ciclo de liofilização. A transição vítrea de um produto liofilizado pode ser estudada e aplicada para melhorar o processamento, a qualidade e estabilidade do produto (Chen, Oakley, 1995).

Sob temperaturas abaixo da transição vítrea, a matriz do soluto encontra-se no estado de um sólido amorfo vítreo. Durante a liofilização, se a temperatura de congelamento ultrapassar a $T_{g}^{\prime}$, a solução amorfa concentrada ficará menos viscosa, podendo causar o colapso do produto. Durante a liofilização, a concentração do soluto da matriz aumenta progressivamente devido à perda de água. A matriz tornase mais rígida e a $T_{g}$ aumenta. O produto pode, então, tolerar o aumento da temperatura sem sofrer o colapso.

A determinação dos parâmetros do processo de liofilização está diretamente relacionada com as características térmicas da formulação e a análise térmica por calorimetria exploratória diferencial (DSC) é um método conveniente para se avaliar estes características (Chen, Oakley, 1995).

A proteína utilizada neste estudo foi a albumina sérica bovina (BSA), amplamente estudada no campo da bioquímica. A BSA é a proteína mais abundante no plasma sanguíneo e serve como depósito, assim como transporte de proteína para numerosos componentes, como cadeia longa de ácidos graxos ou bilirrubina, ligados por alta afinidade à proteína. A estrutura secundária da albumina bovina contém muitos resíduos de cistina e estes são helicoidais em grande parte da cadeia. Apresenta fácil isolamento em grandes quantidades, favorecendo sua alta estabilidade e solubilidade. É a principal proteína que contribui para a pressão coloidal osmótica do sangue e também para o transporte de proteínas para numerosos compostos endógenos e exógenos. Com massa molecular de $66 \mathrm{kDa}$, consiste em uma única cadeia polipeptídica, contendo cerca de 580 aminoácidos (Nakamura et al., 1997). A albumina bovina (BSA) passa por notáveis mudanças reversíveis na conformação, usualmente sob condições não-fisiológicas.

Verificou-se a influência da taxa de congelamento no comportamento físico-químico e estrutural durante a liofilização da albumina bovina, por meio dos dados obtidos por espectroscopia Raman, associados com a análise térmica por DSC.

\section{MATERIAL E MÉTODOS}

Albumina bovina fração $\mathrm{V}$ (fracionamento por metodologia Cohn) pó cristalino da marca INLAB.

Tampão fosfato (pH 7,3) 0,1 M.

\section{Solução de BSA}

Prepararam-se $100 \mathrm{~mL}$ de solução albumina bovina $(100 \mathrm{mg} / \mathrm{mL})$ em tampão Fosfato $(\mathrm{pH} 7,3)$ 0,1M.

\section{Determinação da temperatura de transição vítrea}

A temperatura de transição vítrea $\left(\mathrm{T}_{\mathrm{g}}\right)$ da solução e do pó liofilizado da albumina bovina foi determinada utilizando-se DSC 822 da METTLER TOLEDO. Para a determinação da $\mathrm{T}_{\mathrm{g}}$ das soluções, aproximadamente $3 \mathrm{mg}$ de solução foram pipetadas em recipientes de alumínio ("cadinhos") e resfriadas a uma temperatura de $-50{ }^{\circ} \mathrm{C}$. Após o congelamento, as amostras foram aquecidas até temperatura ambiente, como descrito a seguir:

Para a análise térmica do pó liofilizado pesou-se aproximadamente $3 \mathrm{mg}$ de amostra efetuou-se o congelamento do material até temperatura de $0{ }^{\circ} \mathrm{C}$ seguido de aquecimento até $60{ }^{\circ} \mathrm{C}$. Em todas as etapas, utilizou-se taxa de resfriamento e aquecimento de $5^{\circ} \mathrm{C} / \mathrm{min}$ em atmosfera de nitrogênio com vazão de $50 \mathrm{~mL} / \mathrm{min}$.

\section{Análise estrutural}

A estrutura secundária da albumina bovina (solução e pó liofilizado) foi determinada por espectroscopia RAMAN, utilizando-se espectrômetro da marca BRUKER, IFS 28/N com acessório FRA 106/S. Utilizou-se resolução espectral de $4 \mathrm{~cm}^{-1}$ e 128 números de aquisições. As análises foram conduzidas sob temperatura ambiente. 


\section{Determinação do teor de umidade residual}

A umidade residual do pó liofilizado da albumina bovina foi determinada por metodologia Karl Fisher em equipamento da METTLER TOLEDO DL $31 \mathrm{KARL}$ FISHER TITRATOR.

\section{Liofilização da albumina bovina}

A liofilização foi conduzida em um liofilizador da marca FTS Systems, modelo TDS-00209-A, controlado pelo programa Liphoware.

O congelamento lento (taxa de resfriamento de $2,5^{\circ} \mathrm{C} / \mathrm{min}$ ) foi realizado colocando-se os frascos envasados com BSA em temperatura ambiente diretamente nas prateleiras pré-congeladas de um Ultrafreezer com temperatura final de $-70{ }^{\circ} \mathrm{C} \pm 1{ }^{\circ} \mathrm{C}$. As amostras permaneceram no ultrafreezer por 4 horas.

O congelamento rápido (taxa de resfriamento de $30{ }^{\circ} \mathrm{C} / \mathrm{min}$ ) foi realizado com a imersão das amostras diretamente em nitrogênio líquido.

Após o congelamento das amostras (em ambas as taxas de congelamento), os frascos foram transferidos para as prateleiras pré-congeladas do liofilizador à $-40^{\circ} \mathrm{C} \pm 1{ }^{\circ} \mathrm{C}$.

A secagem primária foi conduzida com temperatura de placa de $-22^{\circ} \mathrm{C} \pm 1{ }^{\circ} \mathrm{C}$, pressão interna na câmara de $300 \mathrm{~m}$ Torr $\pm 5 \mathrm{mTorr}$ e temperatura do condensador de $-90{ }^{\circ} \mathrm{C} \pm 1{ }^{\circ} \mathrm{C}$. A secagem secundária foi conduzida com temperatura de placa de $25^{\circ} \mathrm{C} \pm 1{ }^{\circ} \mathrm{C}$, pressão interna na câmara de $10 \mathrm{mTorr} \pm 5 \mathrm{~m}$ Torr e temperatura do condensador de $-90{ }^{\circ} \mathrm{C} \pm 1{ }^{\circ} \mathrm{C}$ (Fig. 2). As pressões da câmara e do condensador foram avaliadas por um barômetro da marca MKS Baratron Type 122AAbsolute Pressure Transducer. A pressão interna da câmara foi controlada por uma válvula de admissão de ar com filtro de $0.2 \mathrm{~mm}$ PTFE (teflon) estéril acoplada na parte externa e superior da câmara de secagem. O final da liofilização foi determinado por um higrômetro da marca Hygrometer Endress + Hauser Hygroguard 2550 microprocessor controlled trace moisture analyzer. Os frascos foram fechados por rolhas butílicas ainda dentro da câmara sob pressão reduzida de 10 mTorr \pm 5 mTorr.

\section{RESULTADOS E DISCUSSÃO}

Inicialmente, determinou-se a $\mathrm{T}_{\mathrm{g}}$, da solução de BSA para se obter as condições necessárias durante o ciclo de liofilização. A figura 1 mostra a curva de DSC referente à amostra de albumina bovina $(100 \mathrm{mg} / \mathrm{mL})$ em tampão fosfato $(\mathrm{pH} \mathrm{7,3)} \mathrm{durante} \mathrm{a} \mathrm{análise} \mathrm{térmica} \mathrm{da}$ solução congelada.

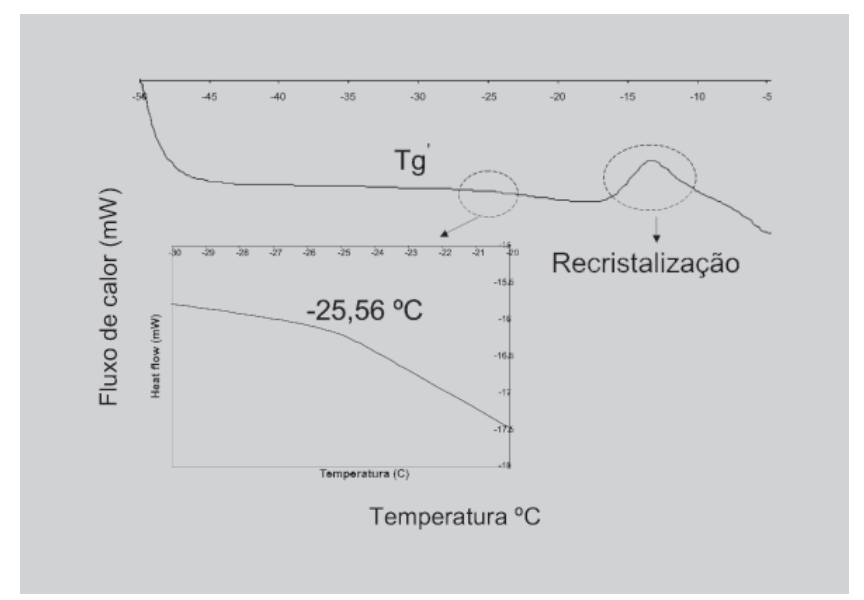

FIGURA 1 - Curva de DSC da solução de albumina bovina $(100 \mathrm{mg} / \mathrm{mL})$ em tampão fosfato $(\mathrm{pH} 7,3$ durante a análise térmica da solução congelada.

Analisando-se a curva, observa-se um declive referente à transição de segunda ordem na faixa de $-25^{\circ} \mathrm{C} \pm$ $0,8^{\circ} \mathrm{C}$ correspondente à $\mathrm{T}_{\mathrm{g}}^{\prime}$. Alguns autores consideram o valor de $\mathrm{T}_{\mathrm{g}}^{\prime}$ como sendo o ponto médio na curva medida pelas extensões da linha de base antes e depois da transição, porém neste estudo considerou-se o início do declive na linha de base como sendo a temperatura crítica para a liofilização da BSA.

Após a $\mathrm{T}_{\mathrm{g}}$, observou-se um pico exotérmico na faixa dos $-14{ }^{\circ} \mathrm{C} \pm 0,7^{\circ} \mathrm{C}$ possivelmente referente à cristalização dos sais do tampão presentes na solução.

À temperatura de $-5^{\circ} \mathrm{C} \pm 0,5^{\circ} \mathrm{C}$ observou-se um pico endotérmico atribuído ao início da fusão do gelo na solução.

Em uma liofilização, durante a secagem primária, quando o gelo é sublimado, o produto deve ser mantido abaixo da temperatura de colapso, que, normalmente, coincide com a transição termotrópica que foi referente à temperatura de transição vítrea da amostra ou como a temperatura de relaxamento da fase amorfa $(T S)$. Além disso, é necessário manter a temperatura da solução abaixo da temperatura de fusão eutética de qualquer componente cristalino. Portanto, estas temperaturas foram determinadas utilizando-se o DSC. A secagem de um produto abaixo da temperatura de colapso tem um custo. Quanto mais baixa a temperatura da amostra, mais lento e mais caro o ciclo de liofilização se torna. Em geral, a liofilização de um produto abaixo de $-40^{\circ} \mathrm{C}$ não é viável. Além disso, há limites físicos nas temperaturas nas quais as amostras podem ser reduzidas, limites esses que dependem do liofilizador e das características da amostra (Carpenter et al., 1997).

Analisando a Figura 2, referente à curva de liofilização da albumina em relação às diferentes taxas de congelamento empregadas, podemos observar diferença 


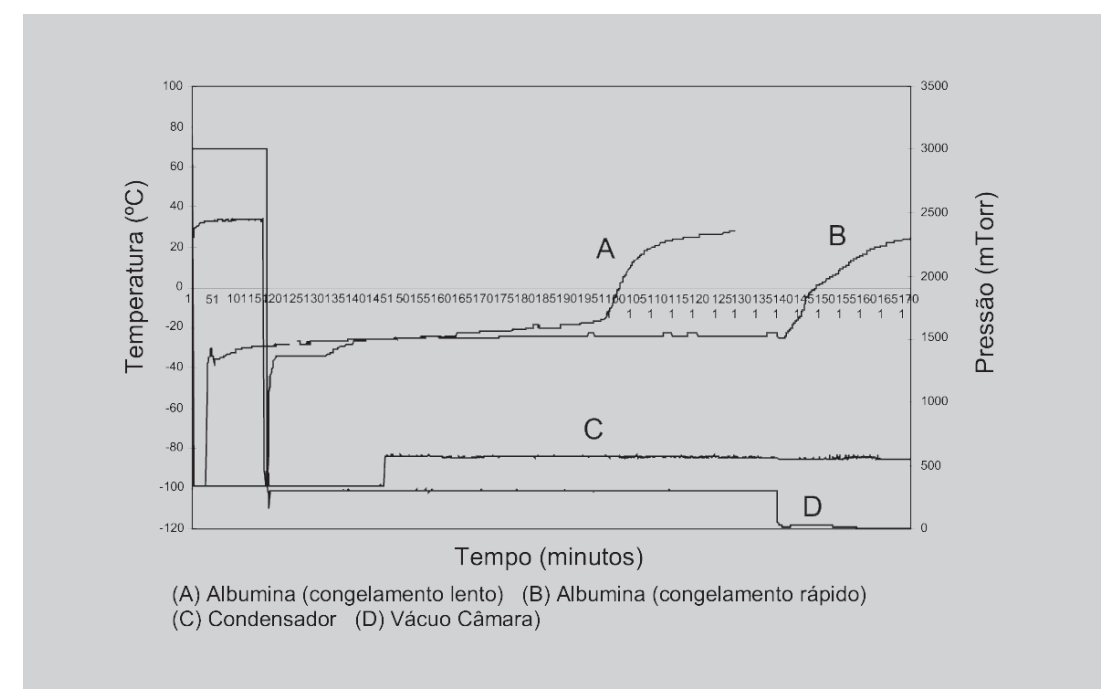

FIGURA 2 - Curva de liofilização da albumina nativa utilizando-se taxas de congelamento de $2,5{ }^{\circ} \mathrm{C} / \mathrm{min}(\mathrm{A})$ e $30^{\circ} \mathrm{C} /$ $\min (\mathrm{B})$.

de sete horas na secagem primária, que está diretamente relacionada com o tamanho, forma e a distribuição dos cristais de gelo formados durante o congelamento.

A liofilização foi conduzida até secagem completa de ambas as amostras, tendo como base o controle de umidade residual do próprio equipamento. As amostras foram congeladas com duas diferentes taxas de congelamento. Foram liofilizadas sob as mesmas condições: temperatura de placa e pressão, em que, a diferença entre a temperatura de placa e a temperatura de colapso do material, $(\mathrm{Tp}-\mathrm{Tc})$, foi constante para ambas as amostras. A taxa de congelamento de $2,5^{\circ} \mathrm{C} / \mathrm{min}$ (Ultrafreezer) induziu a formação de cristais de gelo relativamente maiores do que os cristais de gelo formados durante o congelamento utilizando-se $\mathrm{N}_{2}\left(30^{\circ} \mathrm{C} / \mathrm{min}\right)$. Por esta razão observou-se uma diferença de sete horas e meia na secagem primária das amostras.

Os cristais de gelo formados na amostra durante o congelamento lento, quando sublimados durante a secagem primária, deixam espaços intersticiais que facilitam e aceleram a sublimação na interface de gelo da solução.

Além disso, para assegurar a estabilidade da proteína liofilizada por um longo período, a temperatura de transição vítrea do produto não deve exceder a temperatura de armazenamento planejada. Desde que a água é um agente plasticizante da fase amorfa, é preciso baixa umidade residual para assegurar que a $T_{g}$ do produto liofilizado seja maior do que a temperatura mais alta encontrada durante o transporte e o armazenamento (Carpenter et al., 1997).

Após a liofilização, a albumina bovina pó liofilizada foi submetida à análise térmica por DSC.

As Figuras 3 e 4 apresentam, respectivamente, as curvas de DSC obtidas para os produtos liofilizados submetidos às taxas de congelamento de $2,5^{\circ} \mathrm{C} / \mathrm{min}$ e de $30{ }^{\circ} \mathrm{C} / \mathrm{min}$. Na figura 3 constatou-se um declive na linha de base horizontal na faixa de $48{ }^{\circ} \mathrm{C} \pm 1{ }^{\circ} \mathrm{C}$ durante o aquecimento da albumina bovina pó liofilizado com taxa de congelamento de $2,5^{\circ} \mathrm{C} / \mathrm{min}$. Para a albumina bovina pó liofilizado com taxa de congelamento de $30^{\circ} \mathrm{C} / \mathrm{min}$ esse declive foi observado a $37^{\circ} \mathrm{C} \pm 0,5$ (Figura 4).

Estes decaimentos referem-se à $\mathrm{T}_{\mathrm{g}}$ do pó liofilizado com umidade residual média de $11 \% \pm 1$ e $4,6 \% \pm 1,2$ respectivamente. Esta diferença nos valores de $\mathrm{T}_{\mathrm{g}}$ está relacionada com o conteúdo de água residual após a liofilização, pois a água, considerada um agente plasticizante com valor de $\mathrm{T}_{\mathrm{g}}$ próximo à $-130^{\circ} \mathrm{C}$, influi diretamente nos valores de $\mathrm{T}_{\mathrm{g}}^{\mathrm{e}}$ em um material.

Os valores de $\mathrm{pH}$ da albumina reidratada após a liofilização não apresentaram diferenças significativas (desvio padrão: 0,004).

A média dos valores de $\mathrm{pH}$ das amostras de albumina bovina liofilizada com taxa de congelamento de $2,5^{\circ} \mathrm{C} / \mathrm{min}$ foi de $7,2 \pm 0,1$ e para as amostras de albumina bovina liofilizada com taxa de congelamento de $30{ }^{\circ} \mathrm{C} / \mathrm{min}$ foi de $7,1 \pm 0,1$.

A albumina bovina foi liofilizada nas mesmas condições de secagem (temperatura e pressão), porém variando-se a taxa de congelamento. Observou-se que o tempo de secagem primária foi maior para a albumina liofilizada com taxa de congelamento de $30{ }^{\circ} \mathrm{C} / \mathrm{min}$ resultando em um produto com maior valor de umidade residual, $11 \% \pm 1$, o que permite supor que o congelamento lento com umidade residual de $4,6 \% \pm 1,2$ pode ter cau- 


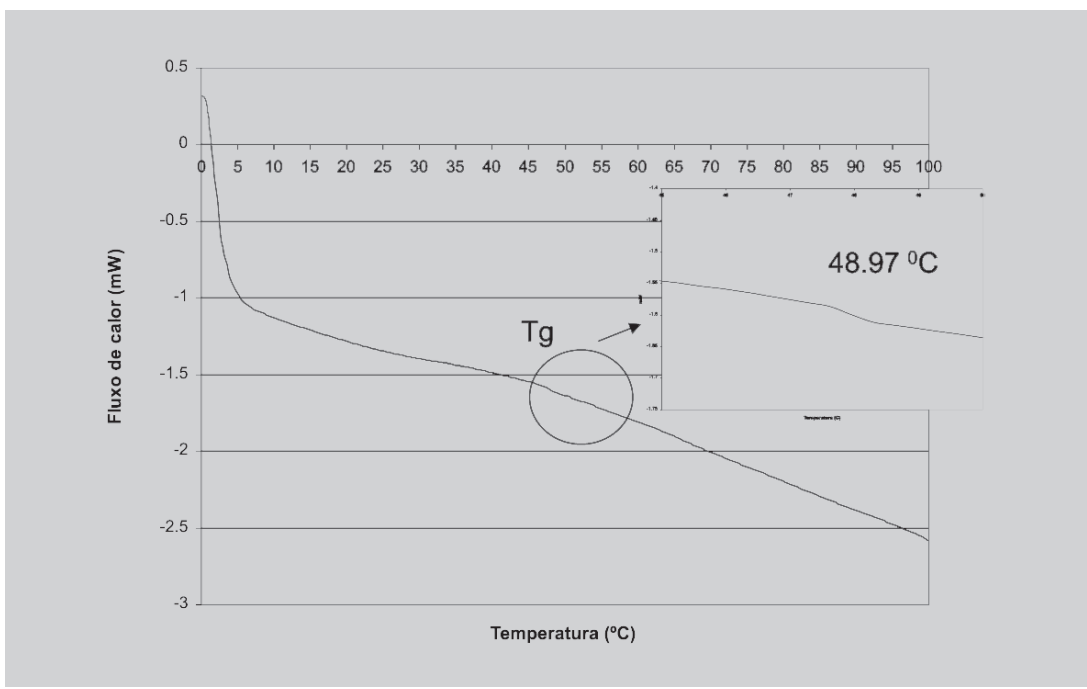

FIGURA 3 - Curva de DSC da albumina bovina pó liofilizado com taxa de congelamento de $30{ }^{\circ} \mathrm{C} / \mathrm{min}$. Umidade residual $11 \% \pm 1$.

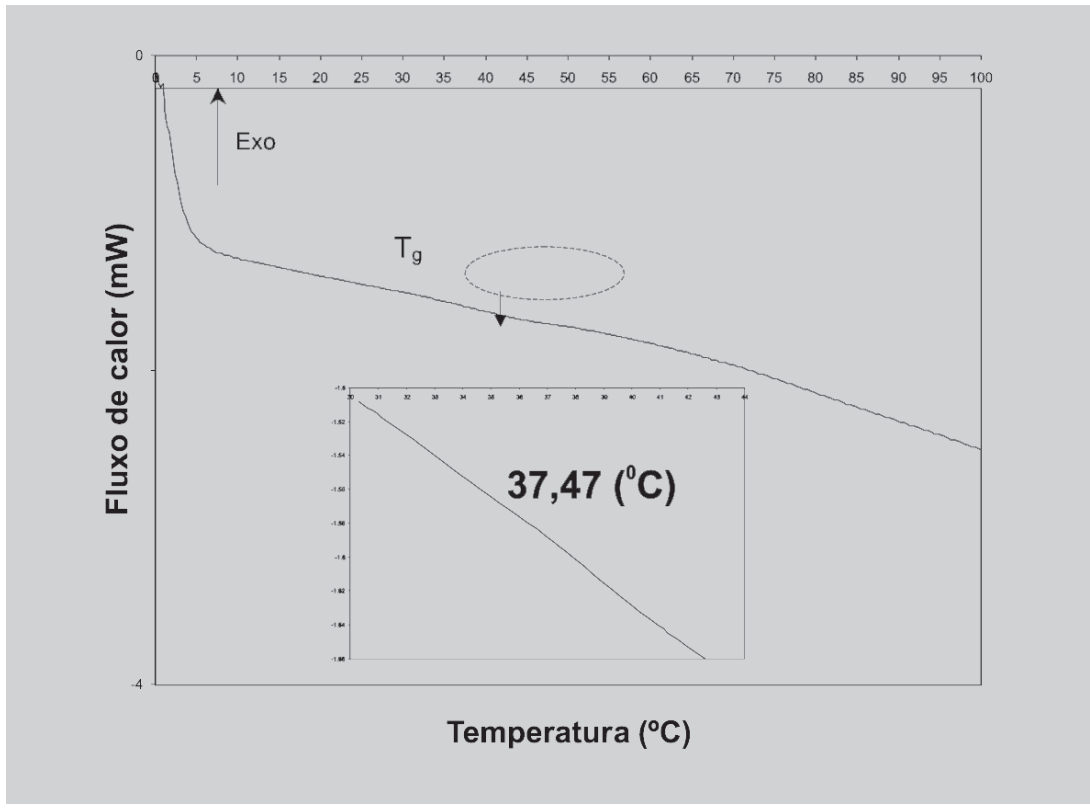

FIGURA 4 - Curva de DSC da albumina bovina pó liofilizado com taxa de congelamento de $30{ }^{\circ} \mathrm{C} / \mathrm{min}$. Umidade residual $4,6 \% \pm 1,2$.

sado danos estruturais liberando a água estrutural da proteína que foi removida durante a liofilização.

Na presença de umidade, as proteínas liofilizadas podem sofrer intercâmbios de pontes de dissulfeto intermoleculares e outras reações que podem levar à inativação da molécula. Tais alterações moleculares foram anteriormente descritas para a insulina humana, toxóide tetânica e interleucina-2 (Roy, Guta, 2004).

O congelamento utilizando-se a taxa de $30{ }^{\circ} \mathrm{C} / \mathrm{min}$ induziu a formação de pequenos cristais de gelo, os quais dificultam a saída do vapor de água durante a secagem primária.

Devido a este fator, supõe-se que a umidade residual da albumina bovina liofilizada utilizando-se taxa de congelamento de $30{ }^{\circ} \mathrm{C} / \mathrm{min}$ foi significativamente maior em razão do tipo de congelamento empregado.

A Figura 5 representa a determinação das regiões da Amida I, II e III por espectroscopia Raman da solução de albumina bovina tampão fosfato $(\mathrm{pH} 7,3,0,1 \mathrm{M})$ largamente usadas para caracterizar a estrutura secundária da cadeia polipeptídica de uma proteína.

A amida I é caracterizada pelo de estiramento $\mathrm{C}=\mathrm{O}$, enquanto que a amida III apresenta grande contribuição na vibração de deformação N-H no plano e pequena contribuição do estiramento C-N. 


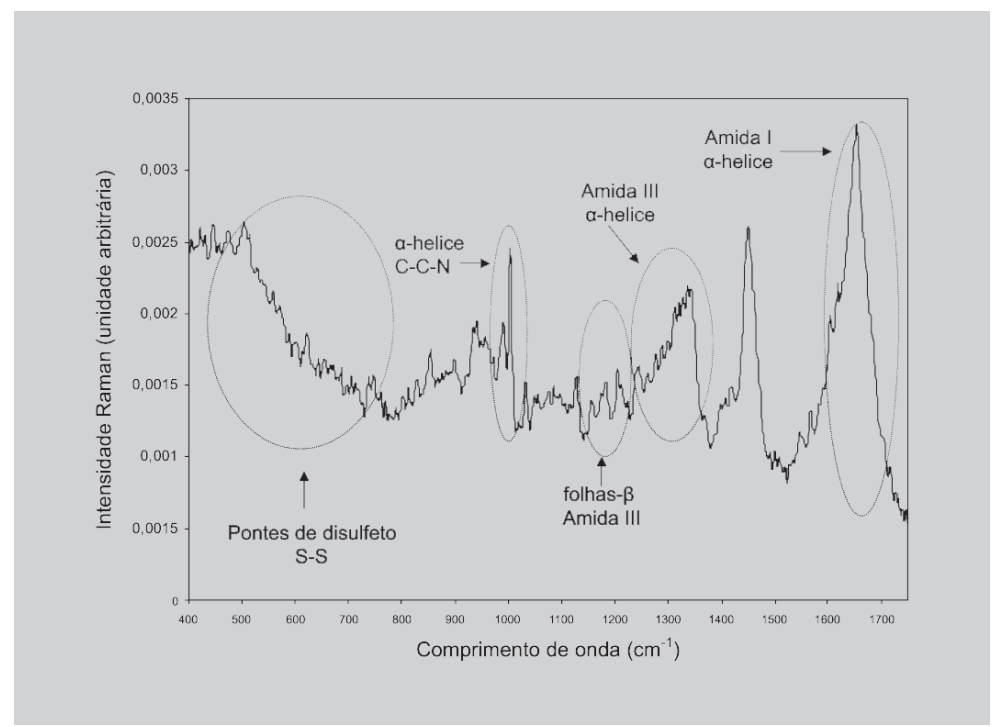

FIGURA 5 - Espectro Raman da solução da albumina bovina (100 mg/mL) em tampão fosfato, 0,1 M, pH 7,3.

Na Tabela I é mostrado o intervalo em que aparecem as freqüências Raman dos modos $v(\mathrm{C}=\mathrm{O})$ da amida I e $\delta(\mathrm{NH})$ da amida III, para as proteínas contendo estruturas secundárias em $\alpha$-hélice, folhas- $\beta$ e estruturas desordenadas.

Estes valores estão bem próximos aos valores encontrados no espectro Raman da solução de albumina bovina.

Estes intervalos espectrais característicos das amidas I e III resultaram de estudos Raman detalhados sobre polipeptídeos modelo, homopolipeptídeos e proteínas de conformação bem conhecida, em que se verificou a correlação entre freqüência e estrutura (Grdadolnik, 2002).

Uma banda intensa na região de $900-1000 \mathrm{~cm}^{-1}$, atribuída ao estiramento $\mathrm{C}_{\mathrm{a}}-\mathrm{C}-\mathrm{N}$, também é sensível à conformação.

TABELA I - Intervalo entre as freqüências Raman dos modos $\mathrm{n}(\mathrm{C}=\mathrm{O})$ da amida I e d $(\mathrm{NH})$ da amida III, para as proteínas contendo estruturas secundárias em $\alpha$-hélice, folhas- $\beta$ e estruturas desordenadas (Grdadolnik, 2002)

\begin{tabular}{lcc}
\hline Conformação & Amida I $\left(\mathrm{cm}^{-1}\right)$ & Amida III $\left(\mathrm{cm}^{-1}\right)$ \\
\hline$\alpha$-hélice & $1645-1660$ & $1265-1300$ \\
Folha- $\beta$ & $1665-1680$ & $1230-1240$ \\
Estruturas & $1660-1670$ & $1240-1260$ \\
desordenadas & & \\
\hline
\end{tabular}

Proteínas contendo ligação dissulfeto, -C-C-S-S-C$\mathrm{C}$-, apresentam banda Raman característica, relativamente intensa, na região $500-800 \mathrm{~cm}^{-1}$, atribuída ao modo de estiramento -S - S-. Existe uma correlação entre esta freqüência e a conformação. Assim, freqüências de v (S - S) em 510,525 e $540 \mathrm{~cm}^{-1}$ são esperadas quando os dois sítios trans em relação aos átomos de enxofre são ocupados, respectivamente, por: 2 átomos de hidrogênio, um hidrogênio e um carbono, ou 2 átomos de carbono.

Os grupos cistina e metionina, em proteínas, dão origem a vibrações de estiramento C-S na região de $600-750 \mathrm{~cm}^{-1}$ (Stuart, 1997).

A albumina nativa contém predominantemente estruturas $\alpha$-hélice, caracterizada por fortes picos de abundância em $1654 \mathrm{~cm}^{-1}$ e $1000 \mathrm{~cm}^{-1}$. Estes resultados estão de acordo com o trabalho realizado por Chen e Lord, (1976).

A variação na intensidade destes picos está relacionada com o conteúdo das estruturas de $\alpha$-hélice.

Analisando-se a Figura 6, observa-se que após a liofilização da albumina bovina, em diferentes taxas de congelamento, ocorreram alterações significativas nas estruturas de $\alpha$-hélice e folhas $\beta$ (faixas espectrais entre 1620 e $1640 \mathrm{~cm}^{-1}$ ), atribuídas às diferenças nas intensidades Raman.

As alterações espectrais relacionadas nestas freqüências dependem da força de ligação entre as pontes de hidrogênio nas estruturas folhas $\beta$ e também da intensidade de ligação nos dipolos de transição entre as cadeias de aminoácidos.

Analisando a Figura 7, a diferença na intensidade das estruturas $\alpha$-hélice $\left(1654 \mathrm{~cm}^{-1}\right.$ e $\left.1000 \mathrm{~cm}^{-1}\right)$ está diretamente relacionada com o nível de desdobramento protéico e agregação.

A agregação protéica induzida pela temperatura também está associada com a formação de estruturas folhas $\beta$ antiparalelas representadas pela banda $1623 \mathrm{~cm}^{-1}$. 


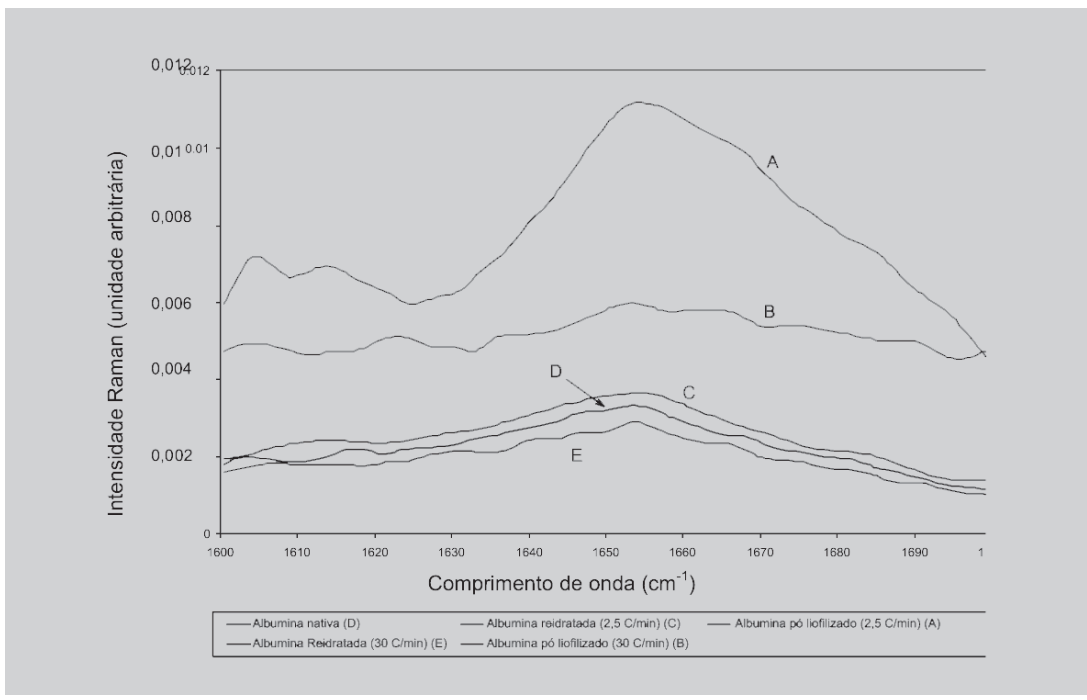

FIGURA 6 - Espectro Raman da albumina bovina pó liofilizado (A e B) e reidratada (C, D e E), na região da Amida I.

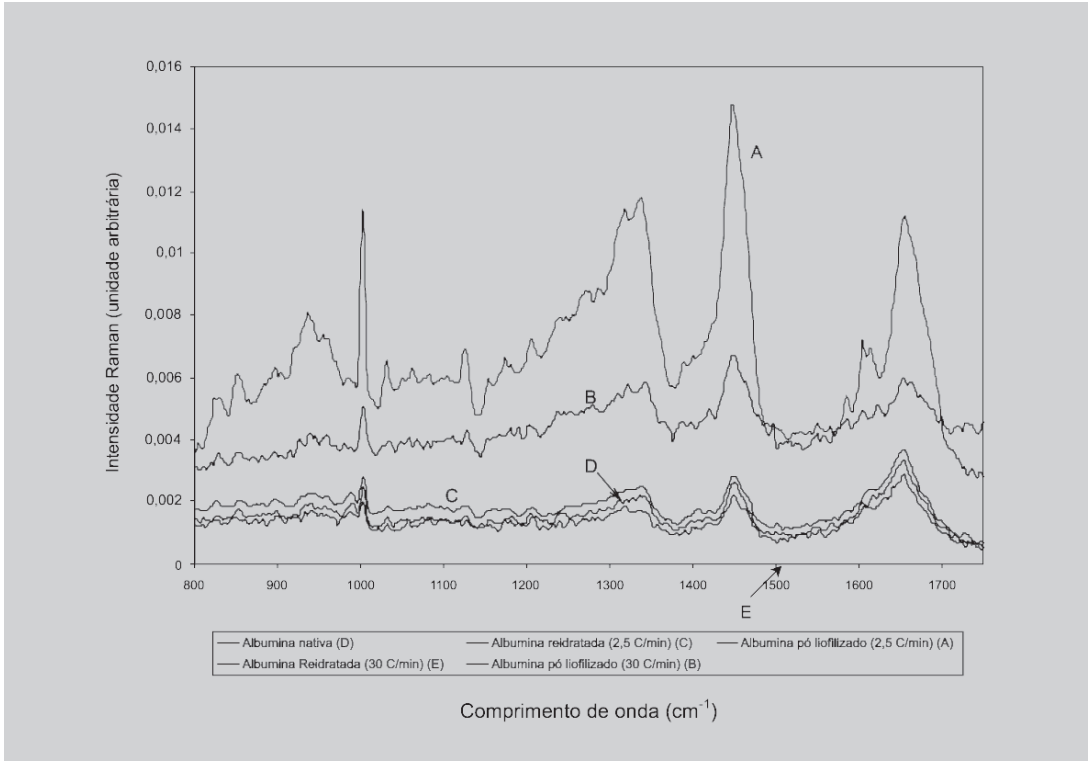

FIGURA 7 - Espectro Raman da albumina bovina pó liofilizado (A e B) e reidratada (C, D e E), na região da Amida II e III.

A albumina liofilizada com taxa de congelamento de $2,5^{\circ} \mathrm{C} / \mathrm{min}$ apresentou maior alteração estrutural, quando comparada à albumina liofilizada com taxa de congelamento de $30^{\circ} \mathrm{C} / \mathrm{min}$.

Notam-se bruscas diferenças nas intensidades das estruturas de $\alpha$-hélice principalmente nas bandas $1654 \mathrm{e}$ $1000 \mathrm{~cm}^{-1}$.

Quando comparada com a albumina liofilizada com taxa de congelamento de $2,5^{\circ} \mathrm{C} / \mathrm{min}$, a albumina congelada em nitrogênio líquido apresentou melhor recuperação do estado nativo. Provavelmente, o congelamento rápido impediu o crescimento abrangente dos cristais de gelo na fase crioconcentrada da proteína, retardando substancialmente a desnaturação da albumina bovina.
A Figura 8 mostra o estiramento das pontes de dissulfeto caracterizadas pelas bandas compreendidas entre 500 e $800 \mathrm{~cm}^{-1}$.

A espectroscopia Raman vem sendo empregada extensivamente para a determinação da conformação das pontes de dissulfeto (S-S) em proteínas e polipeptídeos, pois a freqüência atribuída ao estiramento do modo S-S é sensível à esta conformação (Nakamura et al., 1997).

Podemos observar que a albumina liofilizada com taxa de congelamento de $2,5{ }^{\circ} \mathrm{C} / \mathrm{min}$ apresentou maior grau de estiramento e desordem estrutural relacionados às pontes de disulfeto, quando comparada com a albumina congelada por nitrogênio líquido. 


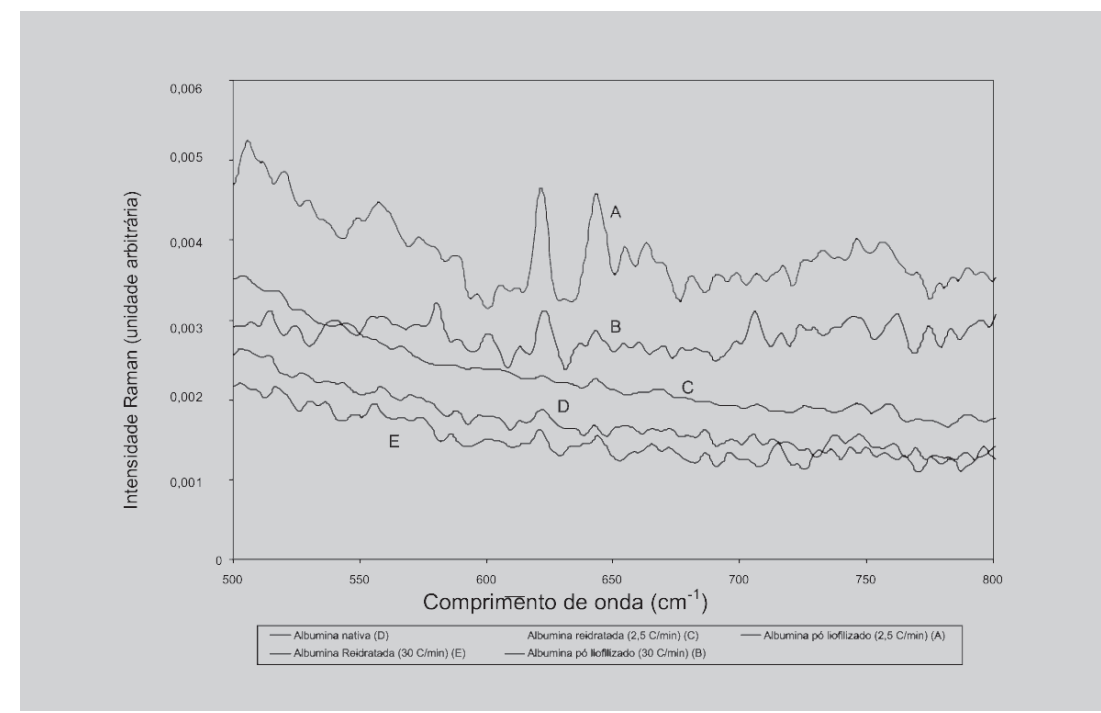

FIGURA 8 - Espectro Raman da albumina bovina pó liofilizado (A e B) e reidratada (C, D e E), na região das pontes de dissulfeto.

Mesmo após a reidratação a albumina não foi capaz de adquirir sua conformação estrutural original.

\section{CONCLUSÕES}

O presente trabalho permitiu estabelecer as seguintes conclusões:

- A liofilização com taxa de congelamento de $30^{\circ} \mathrm{C} / \mathrm{min}$. apresentou menores oscilações espectrais nas regiões da amida I, III e pontes de dissulfeto, favorecendo a manutenção da conformação estrutural da proteína;

- A albumina bovina liofilizada com taxa de congelamento de $30{ }^{\circ} \mathrm{C} / \mathrm{min}$ apresentou desdobramento estrutural durante a liofilização, mas recuperou a conformação original após a reidratação (desdobramento reversível);

- A albumina bovina liofilizada com taxa de congelamento de $2,5^{\circ} \mathrm{C} / \mathrm{min}$ apresentou desdobramento estrutural durante a liofilização e agregação após a reidratação (desdobramento irreversível), característica desfavorável em relação à manutenção da estrutura secundária da proteína;

- O congelamento lento favoreceu a eliminação da água estrutural da albumina bovina nativa diminuindo o tempo de secagem durante a liofilização, porém prejudicando a estrutura conformacional da molécula;

- O controle do teor de umidade residual do pó liofilizado é importante para a manutenção da estrutura secundária da proteína;

- A regeneração da estrutura nativa da proteína, após a reidratação, depende da manutenção de boa parte de sua água estrutural.

\section{ABSTRACT}

\section{Influence of cooling rate on the structural and phase changes during lyophilization of bovine serum albumin}

Lyophilization (freeze-drying) is the most commonly method used to prepare dehydrated proteins, which should have the desired long-term stability at ambient temperatures. However, recent infrared spectroscopic studies have documented that the acute freezing and dehydration stresses of lyophilization can induce protein unfolding. Through Raman spectroscopy associated with thermal analysis using differential scanning calorimetry (DSC), it was studied the influence of cooling rate on the structural and phase changes during lyophilization of bovine serum albumin. It was observed that bovine serum albumin (BSA) lyophilized under slow freezing $\left(2.5^{\circ} \mathrm{C} / \mathrm{min}\right)$ presented higher structure damage than the BSA lyophilized under fast freezing $\left(30^{\circ} \mathrm{C} /\right.$ min) However, the lyophilization process using cooling rate of $30^{\circ} \mathrm{C} / \mathrm{min}$ presented fewer spectra alterations on the Amide I, III and disulfide bridges, supporting the maintenance of protein structural conformation.

UNITERMS: Lyophilization. Raman spectroscopy. Differential scanning calorimetry.

\section{REFERÊNCIAS BIBLIOGRÁFICAS}

CARPENTER, J. F.; PIKAL, M. J.; CHANG, B. S.; RANDOLPH, T. W. Rational design of stable lyophilized protein formulations: some practical advice. Pharm. Res., v. 14, p. 969-975, 1997. 
CARPENTER, J. F.; IZUTSU, K.; RANDOLPH, T. W. Freezing- and drying-induced perturbations of protein structure and mechanisms of protein protection by stabilizing additives. In: REY, L., Freezing-drying/ lyophilization of pharmaceutical and biological products, Louis Rey (ed.), 1999.

CHEN, M. C.; LORD, R. C. Laser-Excited Raman Spectroscopy of Biomolecules VIII. Conformational Study of Bovine Serum Albumin. J. Amer. Chem. Soc., v.98, p.4-10, 1976.

CHEN, T.; OAKLEY, D.M. Thermal analysis of proteins of pharmaceutical interest. Thermochim. Acta, v.248, p. 229-244, 1995.

ECKHARDT, B.M.; OESWEIN, J.Q.; BEWLEY, T.A. Effect of freezing on aggregation of human growth hormone. Pharm. Res., v.8, p.1360-1364, 1991.

GRDADOLNIK, J. Conformation of Bovine Serum Albumin as a Function of hydration monitored by Infrared Spectroscopy. Int. J. Vibr. Spec, Volume 6, 2002.

GRIEBENOW, K.; KLIBANOV, A. M. Lyophilizationinduced reversible changes in the secondary structure of proteins. Proc. Natl. Acad.Sci. USA, v.92, p.10969-10976, 1995.
MURGATROYD, K.; BUTLER, L. D.; KINNARNEY, K.; MONGER, P. Good pharmaceutical freeze-drying practice, Peter Cameron (ed.), 1997.

NAKAMURA, K.; ERA, S.; OZAKI, Y.; SOGAMI, M.; HAYASHI, T.; MURAKAMI, M. Conformational changes in seventeen cystine disulfide bridges of bovine serum albumin proved by Raman spectroscopy. Fed. Eur. Biochem. Soc. Lett., v.417, p. 375-378, 1997.

ROY, I.; GUPTA, M.N. Freeze-drying of proteins: some emerging concerns. Biotechnol. Appl. Biochem., v. 39, p.165-177, 2004.

SANE, S.U.; WONG, R.; HSU, C. C. Raman spectroscopic characterization of drying-induced structural changes in a therapeutic antibody: correlating structural changes with long-term stability. J. Pharm. Sci., v.93, p.1005-18, 2004.

STUART, B. Biological applications of infrared spectroscopy. Anal. Chem. Open Learn., 1997.

WANG, W. Lyophilization and development of solid protein pharmaceuticals. Int. J. Pharm., v.203, p.1-60, 2000.

Recebido para publicação em 21 de fevereiro de 2005. Aceito para publicação em 08 de fevereiro de 2006. 